\title{
TITLE: Cell free and circulating tumor cell based biomarkers in men with metastatic prostate cancer: Tools for Real-Time Precision Medicine?
}

\author{
Authors: David T. Miyamoto, MD, PhD and Richard J. Lee, MD, PhD \\ Institutions: Massachusetts General Hospital Cancer Center (DTM, RJL) and Department of \\ Radiation Oncology, Massachusetts General Hospital (DTM), Harvard Medical School, Boston, \\ MA
}

Acknowledgements: This work was supported by the Department of Defense (DTM) and the Prostate Cancer Foundation (DTM and RJL). RJL has received research funding from Janssen.

\author{
Correspondence to: \\ Dr. David Miyamoto \\ Massachusetts General Hospital \\ 100 Blossom St, Cox 3 \\ Boston, MA 02114 \\ dmiyamoto@mgh.harvard.edu \\ Tel: 617-726-5866 Fax: 617-726-3603
}




\begin{abstract}
The recent expansion of therapeutic options for the treatment of metastatic prostate cancer highlights the need for precision medicine approaches to enable the rational selection of appropriate therapies for individual patients. In this context, circulating biomarkers in the peripheral blood are attractive as readily accessible tools for predicting and monitoring therapeutic response. In the case of circulating tumor cells (CTCs) and circulating tumor DNA (ctDNA), they may also serve as a non-invasive means of assessing molecular aberrations in tumors at multiple time points before and during therapy. These so-called "liquid biopsies" can provide a snapshot view of tumor molecular architecture, and may enable clinicians to monitor the molecular status of tumors as they evolve during treatment, thus allowing for individualized precision therapeutic decisions for patients over time. In this review, we outline recent progress in the field of circulating biomarkers in metastatic prostate cancer, and evaluate their potential for enabling this vision of real-time precision medicine.
\end{abstract}

\title{
INTRODUCTION
}

Prostate cancer remains the second-leading cause of cancer-related death in men in the United States, with an estimated 26,120 deaths in 2016 (1). The past six years have seen the expansion of therapies that improve overall survival (OS) for men with metastatic castration-resistant prostate cancer (mCRPC), with other promising drugs in development (2). However, all of these drugs ultimately have limited efficacy, and primary or acquired resistance to therapy is a significant problem. Monitoring the effectiveness of individual therapies in patients with mCRPC is a uniquely difficult problem because of the high prevalence of bone metastases, which are difficult to quantitate. There exists a need for accurate biomarkers to monitor and predict clinical response in prostate cancer, and thus enable a precision medicine approach to personalizing treatment for the individual patient. A biomarker that can reliably substitute for OS as a surrogate endpoint would also be useful in the design of clinical trials investigating novel therapies, especially in a disease with a growing number of available life-prolonging treatments. 
A biomarker is defined as "a characteristic that is objectively measured and evaluated as an indicator of normal biological processes, pathogenic processes, or pharmacologic responses to a therapeutic intervention" (3). A biomarker can thus provide a clinical measurement for a specific clinical context that may correlate with patient outcomes (prognostic biomarker) or likelihood of response to a specific therapy (predictive biomarker). In many cancers, tissue biomarkers based on the molecular analysis of primary or metastatic tumors have prognostic or predictive value. However, $90 \%$ of men with mCRPC have bone metastases, and tissues from metastatic bone lesions are difficult to reliably obtain and often do not reflect the evolving biology of tumors before and after treatment (4). Therefore, in the setting of metastatic prostate cancer, circulating biomarkers in the peripheral blood are particularly appealing, since they may be assessed non-invasively and repeatedly throughout therapy.

The most widely used circulating biomarker in the care of men with prostate cancer is ProstateSpecific Antigen (PSA, also known as kallikrein-3), a serine protease produced by normal and cancerous prostate epithelial cells. Although characterized as a tumor marker, PSA is produced by normal prostate cells and by other organs in men and women, and is therefore not cancer-, gland-, or gender-specific (5). Most but not all prostate cancers are associated with elevated serum PSA. PSA is regulated by circulating androgens, and its gene expression depends on activation of the androgen receptor (AR). Androgen deprivation therapy (ADT) is typically associated with a decrease in serum PSA, as well as improvement in disease-related symptoms and measurable metastatic disease. In the setting of mCRPC, PSA levels have prognostic value as an independent risk factor for mortality, and post-treatment changes in PSA may reflect changes in tumor burden for some mCPRC therapies (reviewed in detail in (6)). However, posttreatment PSA change has failed to satisfy the definition of a surrogate for OS for multiple therapies with varied mechanisms of action for mCRPC (7-9). Accordingly, no therapy for prostate cancer has been approved solely based on an observed post-treatment decline in serum PSA. This review will focus on alternative circulating biomarkers that have been proposed and studied in recent years. 
Perhaps the most promising of these alternative circulating biomarkers are circulating tumor cells (CTCs) and cell-free DNA, so-called "liquid biopsies" that involve the non-invasive sampling and analysis of tumor-derived cells or nucleic acids in the peripheral blood (10,11). Indeed, these approaches may not only enable the monitoring of treatment responses, but may also provide detailed molecular information about their tumors that can predict response or resistance to specific treatments, and thus guide patients towards the appropriate next lines of therapy. This concept has become increasingly relevant in prostate cancer given our increased level of molecular understanding of prostate cancer through next-generation sequencing studies (12). In this Review, we provide an overview of published data regarding circulating biomarkers for men with mCRPC, with a focus on liquid biopsy approaches, their prognostic and predictive value (see Table 1), and their potential to guide patient care.

\section{CIRCULATING TUMOR CELLS}

CTCs are cancer cells that have been shed from primary or metastatic tumor deposits into the peripheral blood (13-15), and are genetically representative of the primary and metastatic tumors (16-19). Two key limitations of CTC analyses include the rarity of CTCs, estimated at one cell per billion normal blood cells, and the challenging prospect of reliable detection and isolation of these cells. In general, CTC detection strategies include (1) enrichment from blood cells by positively selecting CTCs using antibodies directed against an epithelial cell surface protein, (2) enrichment from blood cells by size-based separation, (3) depletion of blood cells using red blood cell lysis and/or depletion of common leukocyte antigen (CD45)-expressing leukocytes, and (4) CTC identification using immunofluorescence for specific proteins among a spread of the nucleated cells remaining in peripheral blood after red blood cell lysis. Details of the varied approaches to CTC isolation have been described recently in other reviews (13-15, 20). As the only FDA-cleared CTC detection technology, the CellSearch ${ }^{\circledR}$ assay (Veridex, USA) relies on magnetic beads coated with anti-EpCAM antibodies to capture CTCs, followed by confirmation as epithelial cells by positive expression of cytokeratin (CK)-8, CK-18, and CK-19 proteins, and lack of CD45 expression by immunofluorescence staining (21). This platform has several limitations, including its inability to capture mesenchymal CTCs that do not express EpCAM 
(22). Other technologies have been developed to enable the capture of a more comprehensive range of CTC phenotypes, including the EPIC platform and the negative selection-based CTCiChip $(23,24)$. However, CellSearch ${ }^{\circledR}$ has been the primary CTC detection platform used for large-scale patient studies that have assessed CTCs as a biomarker in mCRPC. These studies, described in more detail below, show that enumeration of CTCs correlates with clinical endpoints including survival, and may thus serve as a prognostic biomarker (see Table 1).

\section{CTC Enumeration.}

The prospective study that led to FDA clearance of prognostic use of the CellSearch ${ }^{\circledR}$ assay in prostate cancer, IMMC38, demonstrated that CTCs are an independent predictor of OS (25). This prospective study enrolled 276 patients with progressive mCRPC who were starting a new chemotherapy regimen. CTCs were evaluated in blood samples taken prior to treatment and monthly after initiation of therapy. Patients were categorized as having "unfavorable" $(\geq$ 5 CTCs in $7.5 \mathrm{~mL}$ blood) or "favorable" (< 5 CTCs in $7.5 \mathrm{~mL}$ of blood) CTC counts. IMMC38 met its primary endpoint, demonstrating that unfavorable post-treatment CTC counts were associated with shorter median OS compared with favorable CTC counts ( 9.5 months versus 20.7 months; HR 4.5; $P<0.0001)$. Unfavorable pretreatment counts were also associated with decreased median OS (11.5 months versus 21.7 months). Additionally, patients who converted from unfavorable baseline CTC counts to favorable post-treatment CTC counts had improved median OS (from 6.8 months to 21.3 months); conversely, those who converted from favorable to unfavorable CTC counts had reduced median OS (from >26 months to 9.3 months). CTC abundance was a better predictor of OS than post-treatment changes in serum PSA levels at all time points.

A re-analysis of the IMMC38 trial data focused on the patients receiving first-line chemotherapy, and evaluating CTC counts as a continuous variable, rather than favorable versus unfavorable risk categories, as well as other pre- and post-treatment variables including lactate dehydrogenase levels (LDH) (26). Increased LDH expression has previously been shown to be associated with worse prognosis in mCRPC (27). In IMMC38, higher baseline LDH concentrations (HR 6.44), CTC counts (HR 1.58), and serum PSA (HR 1.26) were significantly associated with shorter OS. During therapy, only baseline LDH and CTC counts at the specific 
timepoint, and not PSA levels or other markers, were associated with survival. These data suggested that CTC abundance combined with baseline LDH could provide a more accurate intermediate end point for clinical trials than post-treatment PSA change. Other studies using CellSearch ${ }^{\circledR}$ have similarly identified serum LDH concentration and CTC counts as independent prognostic factors in mCRPC (28).

CTC enumeration has been evaluated prospectively as an intermediate endpoint in several published clinical trials. SWOG S0421 was a phase III double-blind, randomized placebocontrolled trial evaluating mCRPC patients starting first-line docetaxel chemotherapy with or without atrasentan (29). Atrasentan did not improve OS in this trial (30). Baseline favorable versus unfavorable CTC counts measured on the CellSearch ${ }^{\circledR}$ platform were associated with better OS (26 versus 13 months; HR 2.74, $P=0.001$ ). Any rise in CTC counts after one cycle of docetaxel was significantly associated with worse OS (HR 2.55), whereas falling CTC counts exhibited a nonsignificant trend towards improved OS (29). These data suggest that rising CTC counts during docetaxel chemotherapy may be used for clinical decision-making to change therapy.

COU-AA-301 was a phase III, double-blind, randomized placebo-controlled trial that demonstrated an OS benefit for abiraterone acetate in 1,195 men with mCRPC who had previously received docetaxel (31). COU-AA-301 was the first phase III trial to prospectively define a secondary objective evaluating whether CellSearch ${ }^{\circledR}$-based CTC enumeration could be used as a surrogate efficacy-response biomarker of OS (32). The final analysis included 711 subjects with CTC and LDH data at week 12. Abiraterone treatment (HR 0.70; $P<0.0001$ ), baseline LDH concentration (HR 2.98; $P<0.0001$ ), and CTC count (HR 1.19; $P<0.0001$ ) were prognostic for survival, although PSA was not (HR 1.04; $P=0.1797)$ (33). A "CTC biomarker panel," comprised of CTC count and LDH level, categorized subjects as low risk (CTC $\leq 4$ cells per $7.5 \mathrm{~mL}$ of blood; any $\mathrm{LDH})$, intermediate risk (CTCs $\geq 5$; $\mathrm{LDH} \leq 250 \mathrm{U} / \mathrm{L})$, and high risk $(\mathrm{CTCs} \geq 5 ; \mathrm{LDH}>250 \mathrm{U} / \mathrm{L})$. The $\mathrm{CTC}$ biomarker panel discriminated survival time and satisfied the four Prentice criteria for surrogacy (34), unlike CTC count or LDH as individual variables (32). These prospective, phase III data from SWOG S0421 and COU-AA-301 are encouraging and require validation by ongoing, independent phase III clinical trials. 


\section{CIRCULATING TUMOR DNA}

It has long been appreciated that cell-free fragments of DNA circulate in the blood after being shed by lysed and apoptotic cells $(35,36)$. These fragments are estimated to be 140 to 180 base pairs long, corresponding to nucleosome-protected DNA (37). In healthy individuals, the amount of cell-free DNA (cfDNA) in the blood is thought to be relatively low, approximately in the range of 0 to $50 \mathrm{ng} / \mathrm{mL}$ of blood $(38,39)$. However, cfDNA levels can be higher in certain conditions including inflammation, exercise, or tissue injury, and in cancer patients, the quantity is often several-fold higher and highly variable, in the range of 50 to $5000 \mathrm{ng} / \mathrm{mL}(38,39)$. The portion of cfDNA in patients that is derived from tumors, termed circulating tumor DNA (ctDNA), represents a small fraction of the total circulating nucleic acid burden, with a variable range from $<0.1 \%$ to $>10 \%$ of DNA molecules (40). Since many cancers harbor tumor-specific somatic alterations that are not present in normal cells, ctDNA detection represents a potentially highly specific approach to cancer detection, despite representing a small fraction of cfDNA. The number of circulating mutant gene fragments corresponding to tumor-specific somatic mutations can be very small compared to the number of normal circulating DNA fragments, sometimes less than $0.01 \%$ (40), and there are significant challenges associated with detecting these low-frequency mutations, especially given the high variability in signal. Nevertheless, using novel sensitive detection techniques, the relative quantity of ctDNA in individual cancer patients has been shown to correlate with tumor burden and treatment responses over time (20, 40).

Many ultra-sensitive techniques have been developed to detect and quantitate ctDNA, and these have been reviewed in detail recently $(20,36)$. These techniques include mutation-specific realtime or endpoint PCR (36), as well as digital PCR approaches (41) including BEAMing (42) and droplet digital PCR $(43,44)$. More recently, next generation sequencing approaches have been used to detect and quantify rare mutations in ctDNA, either by PCR or hybridization-based capture of specific genomic loci (45) followed by massively parallel sequencing to detect 
relevant sequence alterations (46-48). Many of these analyses target multiple exons of key genes, but they have also been extended to enable whole-exome analyses (49), as well as detection of chromosomal aberrations and copy number changes at the whole genome level (50, 51). Although a shallow sequencing depth of $0.1 \mathrm{x}$ coverage may be sufficient for the analysis of copy number changes at the whole genome level, a greater sequencing depth of approximately $50 x$ coverage is often necessary for the in depth analysis of structural rearrangements and mutations (51). Thus, given the costs and time required for next-generation sequencing at high coverage, the sequencing strategy may be altered depending on the specific clinical application, with the use of whole genome sequencing at a low sequencing depth to detect copy number changes, and the use of a more targeted deep sequencing approach to identify specific gene breakpoints or mutations.

\section{Circulating Tumor DNA burden.}

Similar to CTC enumeration, measurement of cfDNA and ctDNA burden in the peripheral blood has been correlated with overall tumor burden and potentially prognosis. One study examined both CTCs and cfDNA in the plasma from 81 patients with prostate cancer (52). Plasma cfDNA levels were approximately 2-3 times higher in metastatic compared to localized prostate cancer patients (median $562 \mathrm{ng} / \mathrm{mL}$ vs. $186 \mathrm{ng} / \mathrm{mL} ; \mathrm{P}=0.03$ ), in comparison to healthy men who had a median of $21 \mathrm{ng} / \mathrm{mL}$ of plasma cfDNA. Allelic imbalances representative of ctDNA, detected using a PCR panel of microsatellite markers, were found in $45 \%$ and $59 \%$ of localized and metastatic patients, respectively. In addition, a significant association was noted between the number of CTCs, detected using an epithelial immunospot assay, and allelic imbalance frequencies at markers corresponding to genes encoding demantin, CDKN2/p16, and BRCA1 (52). Thus, the quantitation of both ctDNA and CTCs may provide similar information regarding tumor burden.

Other studies have suggested that cfDNA concentration may be a useful prognostic biomarker to predict outcomes after treatment of mCRPC. In a retrospective study of 59 men with mCRPC starting taxane-based chemotherapy, cfDNA concentration was found to be an independent predictor of OS on multivariate analysis (HR 0.34, $\mathrm{P}=0.032)$ (53). A threshold of $55 \mathrm{ng} / \mathrm{mL}$ cfDNA was significantly associated with a worse PSA response to therapy, with a $<30 \%$ decline 
from baseline $(\mathrm{P}=0.005)$ (53). Other studies also suggest a correlation between changes in plasma cfDNA content and response to chemotherapy, although many of these studies are limited by small sample size and retrospective study designs (54).

\section{MOLECULAR ANALYSIS OF LIQUID BIOPSIES}

Perhaps the most promising applications of CTCs and ctDNA are molecular analyses that can inform the rational selection of appropriate therapies for patients. In the treatment of a patient with $\mathrm{mCRPC}$, alterations in AR may provide the most immediately actionable information with respect to the choice between AR-targeted therapies or non-AR-targeted therapies such as cytotoxic chemotherapy. The reactivation of AR signaling despite ADT that occurs during the evolution of castration resistance underlies the rationale for therapies that target AR signaling, such as abiraterone and enzalutamide (55). However, alterations in the $A R$ gene may be associated with resistance to therapy, including $A R$ gene amplification, point mutations in $A R$, and $A R$ mRNA splice variants (55). For example, the F876L mutation in the ligand-binding domain of AR leads to enzalutamide resistance $(56,57)$, and the AR-V7 mRNA splice variant, which lacks a functional ligand-binding domain and is thus constitutively active, is linked to resistance to abiraterone and enzalutamide, as discussed below (58). Liquid biopsy methods have the potential to detect the presence of such AR alterations in tumors, as well as assess for dynamic changes in AR activity in response to therapies in real-time. It is possible that such assessment of the molecular status of AR may guide the monitoring and application of ARtargeted therapies.

\section{AR Alterations in CTCs}

Several studies have demonstrated the feasibility of detecting $A R$ alterations in CTCs isolated from prostate cancer patients. Fluorescence in situ hybridization (FISH) has been used to characterize copy number amplification of $A R$ in CTCs from patients with $\operatorname{mCRPC}(59,60)$. $A R$ mutations have also been detected in CTCs. For example, one study identified $A R$ mutations in

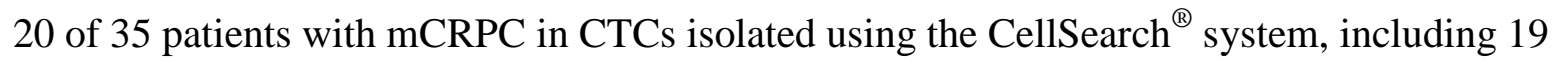
missense mutations, 5 deletions, 1 insertion, and 2 silent mutations (61). Another study 
evaluated the simultaneous detection of $A R$ point mutations and the AR-V7 splice variant in CTCs using qPCR and DNA sequencing in 47 prostate cancer patients starting a new line of therapy (62). Of 37 patients with detectable CTCs, 19 (51\%) harbored $A R$ alterations, including 17 with AR-V7, one with a T878A mutation, and one with both AR-V7 and an H875Y mutation. Although these studies demonstrate the feasibility of using CTCs to non-invasively detect $A R$ alterations in patients with $\mathrm{mCRPC}$, they are limited by their lack of clinical correlations to demonstrate predictive value and clinical utility.

The presence of the AR-V7 splice variant in CTCs has been evaluated as a potential predictive biomarker associated with resistance to enzalutamide and abiraterone in mCRPC (58). In a prospective study of 31 enzalutamide-treated patients and 31 abiraterone-treated patients, $39 \%$ and $19 \%$ respectively had detectable AR-V7 in CTCs prior to initiation of therapy. CTCs were isolated by EpCAM positive selection, and AR-V7 expression was analyzed using a qRT-PCR assay. Patients in the enzalutamide cohort who were positive for AR-V7 had shorter duration of PSA response (PFS 1.4 vs. 6.0 months; $\mathrm{P}<0.001)$, clinical or radiographic PFS (2.1 vs. 6.1 months, $\mathrm{P}<0.001)$, and OS (5.5 months vs. not reached; $\mathrm{P}=0.002)$, compared with patients without detectable AR-V7. Similar results were seen in the abiraterone cohort, where AR-V7 positive patients had lower PSA response rates $(0 \%$ vs. 68\%; $\mathrm{P}=0.004)$, shorter duration of PSA response (1.3 months vs. not reached; $\mathrm{P}<0.001)$, clinical or radiographic PFS (2.3 months vs. not reached; $\mathrm{P}<0.001)$, and OS (10.6 months vs. not reached; $\mathrm{P}=0.006)(58)$. In contrast with ARtargeted therapies, the presence of AR-V7 in CTCs pretreatment was not associated with resistance to docetaxel or cabazitaxel in mCRPC patients starting chemotherapy $(63,64)$. A follow up study of a small cohort of 14 patients showed that AR-V7 can be monitored serially, and that longitudinal AR-V7 dynamics may reflect tumor responses (65). In addition, in a separate cross-sectional cohort study of 161 patients starting therapy with either AR inhibitors or taxanes, the presence of detectable AR-V7 protein in CTCs pre-therapy using the Epic Sciences platform was associated with superior OS with taxanes relative to AR inhibitors (HR 0.24, $\mathrm{P}=0.035)$, thus confirming the earlier findings above (66). However, other reports indicate that the expression of AR-V7 in CTCs does not necessarily preclude a response to abiraterone or enzalutamide, thus cautioning against systematic denial of AR-targeted therapies to these patients (67). Together, these results indicate that larger prospective validation studies are 
necessary to further evaluate AR-V7 in CTCs as a predictive biomarker that may guide patients away from AR-targeted therapies and towards cytotoxic chemotherapy.

Approaches have been developed to directly measure AR activity in CTCs as a dynamic biomarker to predict and monitor responses to therapy. The AR protein translocates to the nucleus in response to activation of AR signaling, and the cytoplasmic (as opposed to nuclear) localization of AR in CTCs from mCRPC patients receiving taxane chemotherapy has been shown to correlate with treatment response (68). A method to dynamically measure downstream effects of AR signaling in prostate CTCs has also been described, using relative levels of PSA and PSMA proteins, which are consistently upregulated or downregulated, respectively, by AR activity (69). These and other studies suggest the potential utility of assessing dynamic signaling pathways in prostate CTCs to predict treatment response to AR-targeted therapies, although further evaluation of these approaches are required in prospective clinical trials.

\section{AR Alterations in ctDNA}

Serial interrogation of ctDNA can detect the emergence of $A R$ alterations over time in mCRPC patients treated with AR-targeted therapies. In recent studies, serial sampling of plasma and tumors from patients with $\mathrm{mCRPC}$ has demonstrated a temporal association between clinical progression on abiraterone and the emergence of $A R$ mutations $(70,71)$. In a study of plasma DNA from 97 men with mCRPC, the emergence of $A R$ mutations (T878A or L702H) was observed in $13 \%$ of patients with disease progression on abiraterone, despite a stable $A R$ copy number throughout therapy (71). Furthermore, patients with $A R$ gain or mutations detected in their ctDNA prior to abiraterone therapy (45\%) were 4.9 times less likely to have a $>50 \%$ decline in PSA, and significantly worse OS (HR 7.33, $\mathrm{P}=1.3 \times 10^{-9}$ ) and PFS (HR 3.73, $\mathrm{P}=5.6 \times 10^{-7}$ ) (71). On multivariate analysis accounting for other clinical factors including serum LDH, altered $A R$ status remained the only significant predictor of OS and PFS. Another study analyzed cfDNA to examine $A R$ copy number variations together with $C Y P 17 A 1$ copy number variations in serum cfDNA from 53 CRPC patients starting abiraterone. Both $A R$ and $C Y P 17 A 1$ gene gain were associated with a significantly lower PFS and OS on univariate analysis, while on multivariate analysis, performance status, PSA decline, $A R$ copy number variation, and DNA concentration 
were associated with OS (72). These data suggest that evaluation of plasma ctDNA for $A R$ alterations may be useful for identifying patients with primary resistance to abiraterone.

Similar to the abiraterone findings, in a retrospective cohort of $39 \mathrm{mCRPC}$ patients commencing enzalutamide therapy, alterations in $A R$ (copy number increase and/or an exon 8 mutation) in pretreatment ctDNA were associated with adverse outcomes, including lower rates of PSA decline $\geq 30 \%$ (and a trend towards lower rates of PSA decline $\geq 50 \%$ ), and shorter time to radiographic/clinical progression (73). AR gene aberrations were observed in 19 of 39 patients (49\%), including 14 with copy number increase, and 5 with AR mutations (H874Y ( $n=2)$, E893K, M895V, and T877A). In a subsequent study, the authors modified their sequencing and data analysis approaches and were able to identify four additional single $A R$ mutations and five mutation combinations associated with $\mathrm{mCRPC}$, with experimental validation of gain-offunction effects (74). A similar study of 65 patients with mCRPC demonstrated that the detection of $A R$ amplification, two or mutations in $A R$, and $R B$ loss in cell-free DNA were associated with worse progression-free survival during treatment with enzalutamide (75). Together, these studies indicate the promise of ctDNA analyses to evaluate $A R$ copy number variations and $A R$ mutations to predict outcomes after AR-targeted therapies. As with AR CTC assays, however, these methods require prospective validation in large clinical trials before they may be routinely applied in the clinic.

\section{Detection of Other Molecular Alterations}

Other genetic alterations have been successfully detected in prostate CTCs, including loss of PTEN (60), amplification of MYC (59), and the TMPRSS2-ERG chromosomal translocation that is seen in half of prostate cancer patients $(60,76)$. Regarding TMPRSS2-ERG, small studies indicate approximately $70 \%$ concordance between the presence of this genetic aberration in CTCs and the primary tumor $(60,76)$. Although TMPRSS2-ERG fusion status can be determined in CTCs, its presence did not predict response to abiraterone treatment in a study of 41 patients with mCRPC (77). Recent technologic advances have also enabled genome-wide analyses of CTCs, such as whole exome sequencing to map the mutational landscape of mCRPC (18), and single cell whole transcriptome RNA-seq to identify pathways potentially associated with antiandrogen resistance including non-canonical Wnt signaling (78). Although these 
studies demonstrate the utility of CTC analyses to detect known and novel molecular alterations in $\mathrm{mCRPC}$, their value as prognostic or predictive biomarkers remains an area of active investigation.

Similarly, sequencing of cfDNA has been used to identify a range of other molecular alterations. Heitzer and colleagues performed whole genome sequencing from plasma in 5 patients with CRPC and 4 patients with castration-sensitive disease, and were able to identify multiple copy number aberrations including losses in $8 \mathrm{p}$ and gains in $8 \mathrm{q}$, as well as the TMPRSS2-ERG rearrangement (51). Methylated glutathione S-transferase 1 (mGSTP1) levels in plasma cfDNA has been prospectively evaluated as a prognostic biomarker in men with mCRPC starting chemotherapy (79). Detectable mGSTP1 in ctDNA at baseline was associated with worse OS, and a decrease in plasma mGSTP1 after one cycle of chemotherapy was associated with PSA response (79). However, additional larger prospective studies are necessary to validate these findings.

\section{Insights into Intratumoral Heterogeneity}

Prostate cancer is known to be a heterogeneous entity, with prostate glands often harboring multiple foci of disease (80). Recent deep sequencing studies have demonstrated the existence of divergent cancer clones within primary tumors (81), and metastatic lesions in men with mCRPC likely arise through polyclonal seeding of divergent clones (82), although some studies suggest that driver lesions are conserved in metastatic lesions within individuals (83). This substantial intratumoral heterogeneity indicates the potential for tumor misclassification when relying on a single tumor biopsy in $\mathrm{mCRPC}$, since molecular signatures may differ considerably depending on the clonal origin of the lesion that was biopsied. In this context, the molecular analysis of CTCs and ctDNA may be advantageous compared to individual tumor biopsies, since these circulating materials are shed from multiple different metastatic lesions, and thus may be more representative of the genetic composition of the total metastatic burden.

Single cell analyses of CTCs isolated from men with prostate cancer demonstrate considerable intracellular heterogeneity consistent with the known intratumoral heterogeneity of prostate cancer. In a single cell RNA-seq study of 77 intact CTCs isolated from 13 patients, single CTCs 
displayed considerable heterogeneity in their transcriptional profiles, including expression of multiple different $A R$ mRNA splice variants across different single cells from the same patient (78). Nevertheless, unsupervised hierarchical clustering analyses showed strong clustering of single CTCs according to their patient of origin, suggesting higher diversity between patients compared to within individual patients. Similar levels of single CTC heterogeneity were observed in AR signaling patterns in patients with $\mathrm{mCRPC}$, assessed through relative protein expression levels of PSA and PSMA (69).

CTC morphology has also been shown to be significantly heterogeneous, and potentially related to patient disease status. In a study of CTCs isolated from 57 prostate cancer patients with either no metastases, nonvisceral metastases, or visceral metastases, 3 distinct subpopulations of CTCs were noted with different nuclear sizes, and CTCs with "very small nuclei" were found to be strongly associated with visceral metastases (84). Interestingly, another study identified unique morphologic characteristics in CTCs from patients with neuroendocrine prostate cancer, including smaller morphology, abnormal nuclear and cytoplasmic features, and lower cytokeratin and AR expression (85).

Serial analyses of plasma cfDNA have also enabled characterization of heterogeneity in tumor clone dynamics reflective of treatment response and disease progression in prostate cancer. In a study of $16 E R G$-rearrangement positive patients, targeted deep sequencing of plasma DNA to detect deletions of 21p22, 8p21, and 10q23 in serial blood samples revealed surprisingly dynamic clonal architectural heterogeneity, where relative frequencies of these common deletions were found to be continuously changing over time (70). Of note, in several cases, initially dominant deletions became subclonal after therapy, and then re-emerged as dominant clones at subsequent time points, suggesting that independent tumor clones from distinct metastases are differentially represented in the peripheral circulation in a dynamic fashion. This complex clonal heterogeneity may originate either from multiple different clones from different tumor foci, or potentially from genetically altered daughter clones arising from a single cell of origin. 


\section{CIRCULATING TUMOR CELLS OR CIRCULATING TUMOR DNA?}

Both CTCs and ctDNA have the potential to be useful for the non-invasive sampling of tumors from the peripheral blood, but the question arises as to which is better suited for clinical applications, and which is closer to routine clinical implementation. The relative quantities of each of these circulating biomarkers are correlated with prognosis in mCRPC, likely due to their reflection of overall tumor burden. Furthermore, both approaches enable the non-invasive molecular analyses of tumors, including the assessment of $A R$ and other molecular alterations. However, since they have orthogonal strengths and weaknesses, CTCs and ctDNA may ultimately serve as complementary biomarkers in the management of mCRPC (see Table 2). ctDNA may be better suited for the detection of actionable mutations, while CTCs are more appropriate for analyses of RNA expression, protein cellular localization, intracellular heterogeneity, and establishment of long-term tumor cell cultures.

Plasma ctDNA has the advantage of generally being easier and less costly to isolate compared to CTCs, and thus may be suitable for large scale serial analyses of tumor-specific mutations in patients. Coupled with the increasing availability and decreasing costs of next-generation sequencing platforms, ctDNA analyses may soon become straightforward to implement into routine clinical practice and clinical trials. However, these platforms for the most part have not yet been standardized, and new tools for ctDNA detection and computational analyses continue to emerge at a rapid pace. A continuing challenge for the use of ctDNA as an analytical tool is the low yield of total cfDNA and the often low percentage of ctDNA among the cfDNA present in the blood of patients. In cfDNA samples without detectable mutations or DNA copy number changes, it is often impossible to distinguish between the actual absence of these changes (true negative) and insufficient yield of ctDNA (false negative). In addition, the specific detection of copy number losses as opposed to gains is particularly challenging in the setting of low ctDNA fractions, and may require ctDNA fractions as high as $10 \%$ (51). The ctDNA fraction tends to correlate with tumor burden, as suggested in studies that reveal a strong relationship between the presence of tumor-derived cfDNA and a CTC count $\geq 5$ cells (73). Thus, further improvements in the specific isolation and sensitive detection of the ctDNA fraction are necessary to enable the application of this technology to a wider spectrum of patients with varying tumor burden. 
In contrast to ctDNA, the isolation of CTCs tends to be more resource-intensive, given the technical challenges of isolating rare and fragile cells from the blood. One advantage of CTC enumeration is the existence of an FDA-cleared standardized platform for CTC enumeration $\left(\right.$ CellSearch $\left.^{\circledR}\right)$, with a large number of patients prospectively studied using this platform to demonstrate the value of CTCs as a prognostic biomarker and a surrogate endpoint in clinical trials. Interestingly, despite the wealth of prospective data supporting its use as a prognostic marker, CTC enumeration with or without other markers such as LDH has not seen widespread adoption in routine clinical practice. Indeed, although these tests can help a clinician predict how well a patient will do, they do not provide information regarding whether an alternative form of therapy may be more appropriate for a given patient. Thus, there is a critical need for predictive biomarkers that can provide actionable information and influence patient clinical management, in contrast to prognostic markers such as CTC enumeration.

The recent demonstration of the potential value of detecting the AR-V7 splice variant in CTCs to predict resistance to AR-targeted therapies suggests that the molecular analysis of CTCs may provide such predictive biomarkers. However, such detailed analyses that go beyond enumeration often require more advanced CTC isolation technologies, many of which are not standardized or widely available. Nevertheless, access to intact CTCs enables a variety of analyses not possible with ctDNA, including RNA-based analyses such as the detection of $A R$ mRNA splice variants and whole transcriptome RNA-seq, and protein-based analyses including AR localization and PSA/PSMA expression, as described above. Other analyses that require intact cells include assessment of the marker of proliferation Ki-67, which in a pilot study exhibited widely variable expression in prostate CTCs (1-81\%), with a higher proliferative index associated with mCRPC (76). The detection of telomerase activity in live CTCs has been shown to be prognostic of overall survival in a large subgroup of the prospective SWOG 0421 trial (HR 1.14; $\mathrm{P}=0.001$ ) (86). The analysis of intact CTCs also enables the direct study of intracellular heterogeneity with regard to cellular morphology and genetic profiles, which may itself be of prognostic value. Perhaps the ultimate application of isolated CTCs is the establishment of CTC cultures for the purpose of individualized testing of drug susceptibility in vitro (87). Pilot studies have demonstrated that culture of CTCs isolated from patients with mCRPC is possible using 
conditions optimized for 3D organoid growth (88), although further optimization of culture conditions are necessary to enable successful culture of samples from patients with lower CTC burden.

In addition to CTCs and ctDNA, an emerging category of potential circulating biomarkers includes extracellular vesicles such as exosomes and oncosomes, which are secreted by normal and cancer cells (89). These 50 to $200 \mathrm{~nm}$ vesicles contain proteins and RNA molecules derived from the membrane and cytoplasm of their donor cells, and are thought to function as regulators of cell-to-cell communication through transfer of biologically active components (90). Proteins such as the multidrug resistance protein 1 (MDR1/ABCB1) have been found to be potentially higher in serum exosomes isolated from men with docetaxel-resistant prostate cancer (91). Further exploration of circulating extracellular vesicles as potential biomarkers in mCRPC is warranted, although much remains to be done with regard to standardization of isolation procedures, the development of robust assays, and their prospective validation in clinical trials.

\section{CONCLUSIONS}

Identifying biomarkers to help clinicians prescribe effective therapies while sparing patients the side effects of treatments that are unlikely to be beneficial remains an important unmet medical need in the care of prostate cancer patients. Circulating biomarkers such as CTCs and ctDNA hold promise as readily accessible sources of tumor-derived material that may be serve as prognostic or predictive biomarkers. This approach has been likened to a liquid biopsy that would be amenable to repetitive evaluations during the course of therapy, providing information about tumor burden as reflected by the number of CTCs or quantity of ctDNA, as well as a window into the molecular architecture of tumors as they evolve during treatment. CTC enumeration has been demonstrated to serve as a reliable prognostic biomarker in mCRPC and a potential surrogate endpoint for clinical trials, especially in combination with LDH. Beyond enumeration, the molecular characterization of CTCs and the analysis of ctDNA can provide actionable information regarding the presence of $A R$ splice variants and $A R$ mutations in patients and the corresponding likelihood of resistance to AR-targeted therapies. Such assays require rigorous standardization of analytic methodology and validation in large-scale, prospective 
clinical trials before they can be incorporated into routine clinical care. It can be envisioned that other liquid biopsy assays will be developed in the future to match men with mCRPC with appropriate targeted therapies based on molecular characteristics of their tumors, such as deficiencies in DNA damage response pathways with PARP inhibitors, or mutations in PIK3CA with PI3K pathway inhibitors. Indeed, technologies for the molecular characterization of both CTCs and ctDNA continue to improve at a rapid pace, and we are moving closer to using these liquid biopsies to tailor treatment for individual patients in real-time. 
Table 1. Prognostic and predictive value of individual circulating biomarkers in mCRPC from selected publications.

\begin{tabular}{|c|c|c|c|c|c|}
\hline Biomarker & Trial & Correlation & Clinical notes & $\begin{array}{l}\text { Prognostic } \\
\text { or predictive } \\
\text { value }\end{array}$ & Ref \\
\hline \multirow[t]{5}{*}{ CTCs } & \multirow[t]{2}{*}{ IMMC38 } & $\begin{array}{l}\text { HR } 4.5 \\
\mathrm{P}<0.0001\end{array}$ & $\begin{array}{l}\text { Unfavorable post-chemo } \\
\text { CTC count associated with } \\
\text { shorter OS }\end{array}$ & Prognostic & (25) \\
\hline & & $\begin{array}{l}\text { HR } 3.3 \\
\mathrm{P}<0.0001\end{array}$ & $\begin{array}{l}\text { Unfavorable pre-chemo } \\
\text { CTC count associated with } \\
\text { shorter OS }\end{array}$ & Prognostic & (25) \\
\hline & \multirow[t]{2}{*}{$\begin{array}{l}\text { SWOG } \\
\text { S0421 }\end{array}$} & $\begin{array}{l}\text { HR } 2.74 \\
P=0.001\end{array}$ & $\begin{array}{l}\text { Favorable pre-docetaxel } \\
\text { CTC count associated with } \\
\text { longer OS }\end{array}$ & Prognostic & (29) \\
\hline & & $\begin{array}{l}\text { HR } 2.55 \\
P=0.041\end{array}$ & $\begin{array}{l}\text { Any rise in CTCs after } 1 \\
\text { cycle of docetaxel } \\
\text { associated with shorter OS }\end{array}$ & Prognostic & (29) \\
\hline & $\begin{array}{l}\text { COU- } \\
\text { AA-301 }\end{array}$ & $\begin{array}{l}\text { HR } 1.19 \\
\mathrm{P}<0.0001\end{array}$ & $\begin{array}{l}\text { Unfavorable pre- } \\
\text { abiraterone CTC count } \\
\text { associated with shorter OS }\end{array}$ & Prognostic & (32) \\
\hline \multirow[t]{2}{*}{ LDH } & IMMC38 & $\begin{array}{l}\text { HR } 6.44 \\
P<0.0001\end{array}$ & $\begin{array}{l}\text { Higher pre-chemo LDH } \\
\text { associated with shorter OS }\end{array}$ & Prognostic & (26) \\
\hline & $\begin{array}{l}\text { COU- } \\
\text { AA-301 }\end{array}$ & $\begin{array}{l}\text { HR } 2.98 \\
\mathrm{P}<0.0001\end{array}$ & $\begin{array}{l}\text { Higher pre-abiraterone } \\
\text { LDH associated with } \\
\text { shorter OS }\end{array}$ & Prognostic & (32) \\
\hline \multirow[t]{2}{*}{ PSA } & $\begin{array}{l}\text { COU- } \\
\text { AA-301 }\end{array}$ & $\begin{array}{l}\text { HR } 1.04 \\
P=0.1797\end{array}$ & $\begin{array}{l}\text { PSA was not associated } \\
\text { with OS }\end{array}$ & N/A & (32) \\
\hline & $\begin{array}{l}\text { COU- } \\
\text { AA-302 }\end{array}$ & $\begin{array}{l}\text { HR } 1.14 \\
\mathrm{P}<0.0001\end{array}$ & $\begin{array}{l}\text { Baseline PSA associated } \\
\text { with OS }\end{array}$ & Prognostic & (92) \\
\hline AR-V7 in CTCs & & HR 6.9 & $\begin{array}{l}\text { Detectable AR-V7 } \\
\text { associated with shorter OS }\end{array}$ & Predictive & $(58)$ \\
\hline
\end{tabular}




\begin{tabular}{|c|c|c|c|c|c|}
\hline & & $\mathrm{P}=0.002$ & on enzalutamide & & \\
\hline & & $\begin{array}{l}\text { HR } 12.7 \\
P=0.006\end{array}$ & $\begin{array}{l}\text { Detectable AR-V7 } \\
\text { associated with shorter OS } \\
\text { on abiraterone }\end{array}$ & Predictive & (58) \\
\hline & & $\mathrm{P}=\mathrm{NS}$ & $\begin{array}{l}\text { Detectable AR-V7 was not } \\
\text { associated with primary } \\
\text { resistance to docetaxel or } \\
\text { cabazitaxel }\end{array}$ & N/A & $\begin{array}{l}(63, \\
64)\end{array}$ \\
\hline & & $\begin{array}{l}\text { HR } 0.24 \\
P=0.035\end{array}$ & $\begin{array}{l}\text { Detectable AR-V7 } \\
\text { predicted superior OS with } \\
\text { taxanes relative to AR } \\
\text { inhibitors }\end{array}$ & Predictive & (66) \\
\hline $\begin{array}{l}\text { TMPRSS2-ERG } \\
\text { in CTCs }\end{array}$ & & $\mathrm{P}=\mathrm{NS}$ & $\begin{array}{l}\text { Detectable TMPRSS2-ERG } \\
\text { did not predict response to } \\
\text { abiraterone }\end{array}$ & N/A & (77) \\
\hline $\begin{array}{l}\text { Telomerase in } \\
\text { CTCs }\end{array}$ & $\begin{array}{l}\text { SWOG } \\
\text { S0421 }\end{array}$ & $\begin{array}{l}\text { HR } 1.14 \\
P=0.001\end{array}$ & $\begin{array}{l}\text { Telomerase activity in live } \\
\text { CTCs associated with } \\
\text { shorter OS }\end{array}$ & Prognostic & (86) \\
\hline cfDNA & & $\begin{array}{l}\text { HR } 0.34 \\
P=0.032\end{array}$ & $\begin{array}{l}\text { Increased cfDNA } \\
\text { associated with worse OS } \\
\text { in men starting taxane } \\
\text { chemo }\end{array}$ & Prognostic & (53) \\
\hline $\begin{array}{l}A R \text { copy number } \\
\text { or mutation in }\end{array}$ & & $\mathrm{P}=0.0026$ & $\begin{array}{l}A R \text { copy number variation } \\
\text { associated with worse OS }\end{array}$ & Prognostic & (72) \\
\hline & & $\begin{array}{l}\text { HR } 7.33 \\
P=1.3 \times 10^{-9}\end{array}$ & $\begin{array}{l}\text { Presence of } A R \text { gain or } \\
\text { mutation in ctDNA prior to } \\
\text { abiraterone associated with } \\
\text { worse OS }\end{array}$ & Predictive & (71) \\
\hline & & $\begin{array}{l}\text { HR } 2.92 \\
P=0.001\end{array}$ & $\begin{array}{l}\text { Presence of } A R \text { gain or } \\
\text { mutation in ctDNA prior to } \\
\text { enzalutamide associated } \\
\text { with worse PFS }\end{array}$ & Predictive & (75) \\
\hline
\end{tabular}


Table 2. Potential complementary clinical applications of CTCs and ctDNA in prostate cancer.

\begin{tabular}{|c|c|c|c|c|}
\hline \multirow[t]{2}{*}{ Application } & \multicolumn{2}{|l|}{ CTCs } & \multicolumn{2}{|l|}{ cfDNA / ctDNA } \\
\hline & Example & Ref & Example & Ref \\
\hline \multirow[t]{2}{*}{$\begin{array}{l}\text { Measure of } \\
\text { tumor burden }\end{array}$} & $\begin{array}{l}\text { Prognostic value: } \\
\text { baseline CTC } \\
\text { measurement }\end{array}$ & $\begin{array}{l}(25,29, \\
32)\end{array}$ & $\begin{array}{l}\text { Prognostic value: } \\
\text { quantification of cfDNA } \\
\text { concentration }\end{array}$ & (53) \\
\hline & $\begin{array}{l}\text { Predictive value: post- } \\
\text { treatment change in } \\
\text { CTCs }\end{array}$ & $(25,29)$ & $\begin{array}{l}\text { Predictive value: } \\
\text { quantification of change } \\
\text { in cfDNA }\end{array}$ & (54) \\
\hline \multirow{6}{*}{$\begin{array}{l}\text { Detection of } \\
\text { DNA/RNA } \\
\text { alterations }\end{array}$} & $\begin{array}{l}\text { Copy number alterations } \\
\text { of } A R\end{array}$ & $(59,60)$ & Gain of $A R$ copy number & $\begin{array}{l}(71-73, \\
75)\end{array}$ \\
\hline & Mutations in $A R(\mathrm{RNA})$ & $(61,62)$ & Mutations in $A R$ (DNA) & $\begin{array}{l}(70,71, \\
73-75)\end{array}$ \\
\hline & $\begin{array}{l}\text { Presence of } A R \text { mRNA } \\
\text { splice variants (e.g. } A R \text { - } \\
V 7)\end{array}$ & $\begin{array}{l}(58,63, \\
64,67,78)\end{array}$ & - & - \\
\hline & $\begin{array}{l}\text { Detection of } \\
\text { translocations (e.g. } \\
\text { TMPRSS2-ERG) }\end{array}$ & $\begin{array}{l}(60,76, \\
77)\end{array}$ & $\begin{array}{l}\text { Detection of } \\
\text { translocations (e.g. } \\
\text { TMPRSS2-ERG) }\end{array}$ & (51) \\
\hline & $\begin{array}{l}\text { Whole exome } \\
\text { sequencing }\end{array}$ & (18) & $\begin{array}{l}\text { Whole genome } \\
\text { sequencing }\end{array}$ & $(51)$ \\
\hline & - & - & $\begin{array}{l}\text { Detection of methylated } \\
\text { cfDNA }(e . g ., G S T P 1)\end{array}$ & (79) \\
\hline \multirow[t]{2}{*}{$\begin{array}{l}\text { Evaluation of } \\
\text { intracellular } \\
\text { heterogeneity }\end{array}$} & $\begin{array}{l}\text { Single cell RNA-seq of } \\
\text { CTCs }\end{array}$ & (78) & $\begin{array}{l}\text { Dynamic changes in } \\
\text { specific deletions (e.g., } \\
21 \mathrm{p} 22,8 \mathrm{p} 21, \text { and } 10 \mathrm{q} 23)\end{array}$ & (70) \\
\hline & $\begin{array}{l}\text { Heterogeneity of CTC } \\
\text { morphology }\end{array}$ & (84) & N/A & - \\
\hline $\begin{array}{l}\text { Protein } \\
\text { localization }\end{array}$ & $\begin{array}{l}\text { AR subcellular } \\
\text { localization }\end{array}$ & (68) & N/A & - \\
\hline
\end{tabular}




\begin{tabular}{|l|l|l|c|c|}
\hline & $\begin{array}{l}\text { AR-V7 protein detection } \\
\text { and localization }\end{array}$ & $(66)$ & N/A & - \\
\hline $\begin{array}{l}\text { Protein } \\
\text { measures of } \\
\text { cellular } \\
\text { activity }\end{array}$ & $\begin{array}{l}\text { AR activity assessed by } \\
\text { relative PSA and PSMA } \\
\text { levels }\end{array}$ & $(69)$ & N/A & - \\
\cline { 2 - 5 } & Telomerase activity & $(86)$ & N/A & - \\
\cline { 2 - 5 } & $\begin{array}{l}\text { Ki-67 as a measure of } \\
\text { proliferation }\end{array}$ & $(76)$ & N/A & - \\
\hline $\begin{array}{l}\text { Establishment } \\
\text { of cultures }\end{array}$ & Organoids from CTCs & $(88)$ & N/A & - \\
\hline
\end{tabular}




\section{REFERENCES}

1. Siegel RL, Miller KD, Jemal A. Cancer statistics, 2016. CA Cancer J Clin 2016; 66: 730.

2. Mateo J, Carreira S, Sandhu S, Miranda S, Mossop H, Perez-Lopez R, et al. DNA-Repair Defects and Olaparib in Metastatic Prostate Cancer. N Engl J Med 2015; 373: 1697-708.

3. Biomarkers Definitions Working G. Biomarkers and surrogate endpoints: preferred definitions and conceptual framework. Clin Pharmacol Ther 2001; 69: 89-95.

4. Saylor PJ, Lee RJ, Smith MR. Emerging therapies to prevent skeletal morbidity in men with prostate cancer. J Clin Oncol 2011; 29: 3705-14.

5. Lovgren J, Valtonen-Andre C, Marsal K, Lilja H, Lundwall A. Measurement of prostatespecific antigen and human glandular kallikrein 2 in different body fluids. J Androl 1999; 20: 348-55.

6. Armstrong AJ, Eisenberger MA, Halabi S, Oudard S, Nanus DM, Petrylak DP, et al. Biomarkers in the management and treatment of men with metastatic castration-resistant prostate cancer. Eur Urol 2012; 61: 549-59.

7. Halabi S, Armstrong AJ, Sartor O, de Bono J, Kaplan E, Lin CY, et al. Prostate-specific antigen changes as surrogate for overall survival in men with metastatic castration-resistant prostate cancer treated with second-line chemotherapy. J Clin Oncol 2013; 31: 3944-50.

8. Kantoff PW, Higano CS, Shore ND, Berger ER, Small EJ, Penson DF, et al. Sipuleucel-T immunotherapy for castration-resistant prostate cancer. N Engl J Med 2010; 363: 411-22. 9. Petrylak DP, Ankerst DP, Jiang CS, Tangen CM, Hussain MH, Lara PN, Jr., et al. Evaluation of prostate-specific antigen declines for surrogacy in patients treated on SWOG 9916. J Natl Cancer Inst 2006; 98: 516-21.

10. Heitzer E, Auer M, Ulz P, Geigl JB, Speicher MR. Circulating tumor cells and DNA as liquid biopsies. Genome Med 2013; 5: 73.

11. Alix-Panabieres C, Pantel K. Clinical Applications of Circulating Tumor Cells and Circulating Tumor DNA as Liquid Biopsy. Cancer Discov 2016; 6: 479-91.

12. Robinson D, Van Allen EM, Wu YM, Schultz N, Lonigro RJ, Mosquera JM, et al. Integrative clinical genomics of advanced prostate cancer. Cell 2015; 161: 1215-28.

13. Miyamoto DT, Sequist LV, Lee RJ. Circulating tumour cells-monitoring treatment response in prostate cancer. Nat Rev Clin Oncol 2014; 11: 401-12.

14. Li J, Gregory SG, Garcia-Blanco MA, Armstrong AJ. Using circulating tumor cells to inform on prostate cancer biology and clinical utility. Crit Rev Clin Lab Sci 2015; 52: 191-210.

15. Alix-Panabieres C, Pantel K. Challenges in circulating tumour cell research. Nat Rev Cancer 2014; 14: 623-31.

16. Fehm T, Sagalowsky A, Clifford E, Beitsch P, Saboorian H, Euhus D, et al. Cytogenetic evidence that circulating epithelial cells in patients with carcinoma are malignant. Clin Cancer Res 2002; 8: 2073-84.

17. Heitzer E, Auer M, Gasch C, Pichler M, Ulz P, Hoffmann EM, et al. Complex tumor genomes inferred from single circulating tumor cells by array-CGH and next-generation sequencing. Cancer Res 2013; 73: 2965-75.

18. Lohr JG, Adalsteinsson VA, Cibulskis K, Choudhury AD, Rosenberg M, Cruz-Gordillo $\mathrm{P}$, et al. Whole-exome sequencing of circulating tumor cells provides a window into metastatic prostate cancer. Nat Biotechnol 2014; 32: 479-84. 
19. Shaffer DR, Leversha MA, Danila DC, Lin O, Gonzalez-Espinoza R, Gu B, et al. Circulating tumor cell analysis in patients with progressive castration-resistant prostate cancer. Clin Cancer Res 2007; 13: 2023-9.

20. Haber DA, Velculescu VE. Blood-based analyses of cancer: circulating tumor cells and circulating tumor DNA. Cancer Discov 2014; 4: 650-61.

21. FDA Clearance Document for Veridex LLC. CellSearch(TM) Circulating Tumor Cell

Kit. Premarket notification - expanded indications for use - metastatic prostate cancer. February 26, 2008. http://accessdata.fda.gov/cdrh_docs/pdf7/K073338. Accessed January 28, 2014.

22. Armstrong AJ, Marengo MS, Oltean S, Kemeny G, Bitting RL, Turnbull JD, et al. Circulating tumor cells from patients with advanced prostate and breast cancer display both epithelial and mesenchymal markers. Mol Cancer Res 2011; 9: 997-1007.

23. Marrinucci D, Bethel K, Kolatkar A, Luttgen MS, Malchiodi M, Baehring F, et al. Fluid biopsy in patients with metastatic prostate, pancreatic and breast cancers. Phys Biol 2012; 9: 016003.

24. Ozkumur E, Shah AM, Ciciliano JC, Emmink BL, Miyamoto DT, Brachtel E, et al. Inertial focusing for tumor antigen-dependent and -independent sorting of rare circulating tumor cells. Sci Transl Med 2013; 5: 179 ra47.

25. de Bono JS, Scher HI, Montgomery RB, Parker C, Miller MC, Tissing H, et al.

Circulating tumor cells predict survival benefit from treatment in metastatic castration-resistant prostate cancer. Clin Cancer Res 2008; 14: 6302-9.

26. Scher HI, Jia X, de Bono JS, Fleisher M, Pienta KJ, Raghavan D, et al. Circulating tumour cells as prognostic markers in progressive, castration-resistant prostate cancer: a reanalysis of IMMC38 trial data. Lancet Oncol 2009; 10: 233-9.

27. Halabi S, Small EJ, Kantoff PW, Kattan MW, Kaplan EB, Dawson NA, et al. Prognostic model for predicting survival in men with hormone-refractory metastatic prostate cancer. J Clin Oncol 2003; 21: 1232-7.

28. Goodman OB, Jr., Fink LM, Symanowski JT, Wong B, Grobaski B, Pomerantz D, et al. Circulating tumor cells in patients with castration-resistant prostate cancer baseline values and correlation with prognostic factors. Cancer Epidemiol Biomarkers Prev 2009; 18: 1904-13.

29. Goldkorn A, Ely B, Quinn DI, Tangen CM, Fink LM, Xu T, et al. Circulating tumor cell counts are prognostic of overall survival in SWOG S0421: a phase III trial of docetaxel with or without atrasentan for metastatic castration-resistant prostate cancer. J Clin Oncol 2014; 32: 1136-42.

30. Quinn DI, Tangen CM, Hussain M, Lara PN, Jr., Goldkorn A, Moinpour CM, et al. Docetaxel and atrasentan versus docetaxel and placebo for men with advanced castrationresistant prostate cancer (SWOG S0421): a randomised phase 3 trial. Lancet Oncol 2013; 14 : 893-900.

31. de Bono JS, Logothetis CJ, Molina A, Fizazi K, North S, Chu L, et al. Abiraterone and increased survival in metastatic prostate cancer. N Engl J Med 2011; 364: 1995-2005.

32. Scher HI, Heller G, Molina A, Attard G, Danila DC, Jia X, et al. Circulating tumor cell biomarker panel as an individual-level surrogate for survival in metastatic castration-resistant prostate cancer. J Clin Oncol 2015; 33: 1348-55.

33. Scher HI, Heller G, Molina A, Kheoh TS, Attard G, Moreira J, et al. Evaluation of circulating tumor cell (CTC) enumeration as an efficacy response biomarker of overall survival (OS) in metastatic castration-resistant prostate cancer (mCRPC): Planned final analysis (FA) of COU-AA-301, a randomized, double-blind, placebo-controlled, phase III study of abiraterone 
acetate (AA) plus low-dose prednisone (P) post docetaxel. J Clin Oncol 2011; 29: Suppl LBA4517.

34. Prentice RL. Surrogate endpoints in clinical trials: definition and operational criteria. Stat Med 1989; 8: 431-40.

35. Stroun M, Lyautey J, Lederrey C, Olson-Sand A, Anker P. About the possible origin and mechanism of circulating DNA apoptosis and active DNA release. Clin Chim Acta 2001; 313: $139-42$.

36. Heitzer E, Ulz P, Geigl JB. Circulating tumor DNA as a liquid biopsy for cancer. Clin Chem 2015; 61: 112-23.

37. Fan HC, Blumenfeld YJ, Chitkara U, Hudgins L, Quake SR. Analysis of the size distributions of fetal and maternal cell-free DNA by paired-end sequencing. Clin Chem 2010; 56: 1279-86.

38. Leon SA, Shapiro B, Sklaroff DM, Yaros MJ. Free DNA in the serum of cancer patients and the effect of therapy. Cancer Res 1977; 37: 646-50.

39. Perkins G, Yap TA, Pope L, Cassidy AM, Dukes JP, Riisnaes R, et al. Multi-purpose utility of circulating plasma DNA testing in patients with advanced cancers. PLoS One 2012; 7 : e47020.

40. Diehl F, Schmidt K, Choti MA, Romans K, Goodman S, Li M, et al. Circulating mutant DNA to assess tumor dynamics. Nat Med 2008; 14: 985-90.

41. Vogelstein B, Kinzler KW. Digital PCR. Proc Natl Acad Sci U S A 1999; 96: 9236-41.

42. Dressman D, Yan H, Traverso G, Kinzler KW, Vogelstein B. Transforming single DNA molecules into fluorescent magnetic particles for detection and enumeration of genetic variations. Proc Natl Acad Sci U S A 2003; 100: 8817-22.

43. Hindson BJ, Ness KD, Masquelier DA, Belgrader P, Heredia NJ, Makarewicz AJ, et al. High-throughput droplet digital PCR system for absolute quantitation of DNA copy number. Anal Chem 2011; 83: 8604-10.

44. Pekin D, Skhiri Y, Baret JC, Le Corre D, Mazutis L, Salem CB, et al. Quantitative and sensitive detection of rare mutations using droplet-based microfluidics. Lab Chip 2011; 11: 2156-66.

45. Thompson JD, Shibahara G, Rajan S, Pel J, Marziali A. Winnowing DNA for rare sequences: highly specific sequence and methylation based enrichment. PLoS One 2012; 7 : e31597.

46. Kinde I, Wu J, Papadopoulos N, Kinzler KW, Vogelstein B. Detection and quantification of rare mutations with massively parallel sequencing. Proc Natl Acad Sci U S A 2011; 108: 9530-5.

47. Forshew T, Murtaza M, Parkinson C, Gale D, Tsui DW, Kaper F, et al. Noninvasive identification and monitoring of cancer mutations by targeted deep sequencing of plasma DNA. Sci Transl Med 2012; 4: 136ra68.

48. Newman AM, Bratman SV, To J, Wynne JF, Eclov NC, Modlin LA, et al. An ultrasensitive method for quantitating circulating tumor DNA with broad patient coverage. Nat Med 2014; 20: 548-54.

49. Murtaza M, Dawson SJ, Tsui DW, Gale D, Forshew T, Piskorz AM, et al. Non-invasive analysis of acquired resistance to cancer therapy by sequencing of plasma DNA. Nature 2013; 497: 108-12. 
50. Leary RJ, Sausen M, Kinde I, Papadopoulos N, Carpten JD, Craig D, et al. Detection of chromosomal alterations in the circulation of cancer patients with whole-genome sequencing. Sci Transl Med 2012; 4: 162ra54.

51. Heitzer E, Ulz P, Belic J, Gutschi S, Quehenberger F, Fischereder K, et al. Tumorassociated copy number changes in the circulation of patients with prostate cancer identified through whole-genome sequencing. Genome Med 2013; 5: 30.

52. Schwarzenbach H, Alix-Panabieres C, Muller I, Letang N, Vendrell JP, Rebillard X, et al. Cell-free tumor DNA in blood plasma as a marker for circulating tumor cells in prostate cancer. Clin Cancer Res 2009; 15: 1032-8.

53. Kienel A, Porres D, Heidenreich A, Pfister D. cfDNA as a Prognostic Marker of Response to Taxane Based Chemotherapy in Patients with Prostate Cancer. J Urol 2015; 194 : 966-71.

54. Kwee S, Song MA, Cheng I, Loo L, Tiirikainen M. Measurement of circulating cell-free DNA in relation to $18 \mathrm{~F}$-fluorocholine PET/CT imaging in chemotherapy-treated advanced prostate cancer. Clin Transl Sci 2012; 5: 65-70.

55. Watson PA, Arora VK, Sawyers CL. Emerging mechanisms of resistance to androgen receptor inhibitors in prostate cancer. Nat Rev Cancer 2015; 15: 701-11.

56. Balbas MD, Evans MJ, Hosfield DJ, Wongvipat J, Arora VK, Watson PA, et al.

Overcoming mutation-based resistance to antiandrogens with rational drug design. eLife 2013; 2: e00499.

57. Joseph JD, Lu N, Qian J, Sensintaffar J, Shao G, Brigham D, et al. A clinically relevant androgen receptor mutation confers resistance to second-generation antiandrogens enzalutamide and ARN-509. Cancer Discov 2013; 3: 1020-9.

58. Antonarakis ES, Lu C, Wang H, Luber B, Nakazawa M, Roeser JC, et al. AR-V7 and Resistance to Enzalutamide and Abiraterone in Prostate Cancer. N Engl J Med 2014.

59. Leversha MA, Han J, Asgari Z, Danila DC, Lin O, Gonzalez-Espinoza R, et al.

Fluorescence in situ hybridization analysis of circulating tumor cells in metastatic prostate cancer. Clin Cancer Res 2009; 15: 2091-7.

60. Attard G, Swennenhuis JF, Olmos D, Reid AH, Vickers E, A'Hern R, et al.

Characterization of ERG, AR and PTEN gene status in circulating tumor cells from patients with castration-resistant prostate cancer. Cancer Res 2009; 69: 2912-8.

61. Jiang Y, Palma JF, Agus DB, Wang Y, Gross ME. Detection of androgen receptor mutations in circulating tumor cells in castration-resistant prostate cancer. Clin Chem 2010; 56: $1492-5$.

62. Steinestel J, Luedeke M, Arndt A, Schnoeller TJ, Lennerz JK, Wurm C, et al. Detecting predictive androgen receptor modifications in circulating prostate cancer cells. Oncotarget 2015. 63. Antonarakis ES, Lu C, Luber B, Wang H, Chen Y, Nakazawa M, et al. Androgen Receptor Splice Variant 7 and Efficacy of Taxane Chemotherapy in Patients With Metastatic Castration-Resistant Prostate Cancer. JAMA Oncol 2015; 1: 582-91.

64. Onstenk W, Sieuwerts AM, Kraan J, Van M, Nieuweboer AJ, Mathijssen RH, et al. Efficacy of Cabazitaxel in Castration-resistant Prostate Cancer Is Independent of the Presence of AR-V7 in Circulating Tumor Cells. Eur Urol 2015; 68: 939-45.

65. Nakazawa M, Lu C, Chen Y, Paller CJ, Carducci MA, Eisenberger MA, et al. Serial blood-based analysis of AR-V7 in men with advanced prostate cancer. Ann Oncol 2015; 26: 1859-65. 
66. Scher HI, Lu D, Schreiber NA, Louw J, Graf RP, Vargas HA, et al. Association of ARV7 on Circulating Tumor Cells as a Treatment-Specific Biomarker With Outcomes and Survival in Castration-Resistant Prostate Cancer. JAMA Oncol 2016.

67. Bernemann C, Schnoeller TJ, Luedeke M, Steinestel K, Boegemann M, Schrader AJ, et al. Expression of AR-V7 in Circulating Tumour Cells Does Not Preclude Response to Next Generation Androgen Deprivation Therapy in Patients with Castration Resistant Prostate Cancer. Eur Urol 2016.

68. Darshan MS, Loftus MS, Thadani-Mulero M, Levy BP, Escuin D, Zhou XK, et al. Taxane-induced blockade to nuclear accumulation of the androgen receptor predicts clinical responses in metastatic prostate cancer. Cancer Res 2011; 71: 6019-29.

69. Miyamoto DT, Lee RJ, Stott SL, Ting DT, Wittner BS, Ulman M, et al. Androgen receptor signaling in circulating tumor cells as a marker of hormonally responsive prostate cancer. Cancer Discov 2012; 2: 995-1003.

70. Carreira S, Romanel A, Goodall J, Grist E, Ferraldeschi R, Miranda S, et al. Tumor clone dynamics in lethal prostate cancer. Sci Transl Med 2014; 6: 254ra125.

71. Romanel A, Gasi Tandefelt D, Conteduca V, Jayaram A, Casiraghi N, Wetterskog D, et al. Plasma AR and abiraterone-resistant prostate cancer. Sci Transl Med 2015; 7: 312re10.

72. Salvi S, Casadio V, Conteduca V, Burgio SL, Menna C, Bianchi E, et al. Circulating cellfree AR and CYP17A1 copy number variations may associate with outcome of metastatic castration-resistant prostate cancer patients treated with abiraterone. Br J Cancer 2015; 112: 1717-24.

73. Azad AA, Volik SV, Wyatt AW, Haegert A, Le Bihan S, Bell RH, et al. Androgen Receptor Gene Aberrations in Circulating Cell-Free DNA: Biomarkers of Therapeutic Resistance in Castration-Resistant Prostate Cancer. Clin Cancer Res 2015; 21: 2315-24.

74. Lallous N, Volik SV, Awrey S, Leblanc E, Tse R, Murillo J, et al. Functional analysis of androgen receptor mutations that confer anti-androgen resistance identified in circulating cellfree DNA from prostate cancer patients. Genome Biol 2016; 17: 10.

75. Wyatt AW, Azad AA, Volik SV, Annala M, Beja K, McConeghy B, et al. Genomic Alterations in Cell-Free DNA and Enzalutamide Resistance in Castration-Resistant Prostate Cancer. JAMA Oncol 2016.

76. Stott SL, Lee RJ, Nagrath S, Yu M, Miyamoto DT, Ulkus L, et al. Isolation and characterization of circulating tumor cells from patients with localized and metastatic prostate cancer. Sci Transl Med 2010; 2: 25ra3.

77. Danila DC, Anand A, Sung CC, Heller G, Leversha MA, Cao L, et al. TMPRSS2-ERG status in circulating tumor cells as a predictive biomarker of sensitivity in castration-resistant prostate cancer patients treated with abiraterone acetate. Eur Urol 2011; 60: 897-904.

78. Miyamoto DT, Zheng Y, Wittner BS, Lee RJ, Zhu H, Broderick KT, et al. RNA-Seq of single prostate CTCs implicates noncanonical Wnt signaling in antiandrogen resistance. Science 2015; 349: 1351-6.

79. Mahon KL, Qu W, Devaney J, Paul C, Castillo L, Wykes RJ, et al. Methylated Glutathione S-transferase 1 (mGSTP1) is a potential plasma free DNA epigenetic marker of prognosis and response to chemotherapy in castrate-resistant prostate cancer. Br J Cancer 2014; 111: 1802-9.

80. Andreoiu M, Cheng L. Multifocal prostate cancer: biologic, prognostic, and therapeutic implications. Hum Pathol 2010; 41: 781-93. 
81. Cooper CS, Eeles R, Wedge DC, Van Loo P, Gundem G, Alexandrov LB, et al. Analysis of the genetic phylogeny of multifocal prostate cancer identifies multiple independent clonal expansions in neoplastic and morphologically normal prostate tissue. Nat Genet 2015; 47: 367-

72.

82. Gundem G, Van Loo P, Kremeyer B, Alexandrov LB, Tubio JM, Papaemmanuil E, et al. The evolutionary history of lethal metastatic prostate cancer. Nature 2015; 520: 353-7.

83. Kumar A, Coleman I, Morrissey C, Zhang X, True LD, Gulati R, et al. Substantial interindividual and limited intraindividual genomic diversity among tumors from men with metastatic prostate cancer. Nat Med 2016; 22: 369-78.

84. Chen JF, Ho H, Lichterman J, Lu YT, Zhang Y, Garcia MA, et al. Subclassification of prostate cancer circulating tumor cells by nuclear size reveals very small nuclear circulating tumor cells in patients with visceral metastases. Cancer 2015; 121: 3240-51.

85. Beltran H, Jendrisak A, Landers M, Mosquera JM, Kossai M, Louw J, et al. The Initial Detection and Partial Characterization of Circulating Tumor Cells in Neuroendocrine Prostate Cancer. Clin Cancer Res 2016; 22: 1510-9.

86. Goldkorn A, Ely B, Tangen CM, Tai YC, Xu T, Li H, et al. Circulating tumor cell telomerase activity as a prognostic marker for overall survival in SWOG 0421: a phase III metastatic castration resistant prostate cancer trial. Int J Cancer 2015; 136: 1856-62.

87. Yu M, Bardia A, Aceto N, Bersani F, Madden MW, Donaldson MC, et al. Cancer therapy. Ex vivo culture of circulating breast tumor cells for individualized testing of drug susceptibility. Science 2014; 345: 216-20.

88. Gao D, Vela I, Sboner A, Iaquinta PJ, Karthaus WR, Gopalan A, et al. Organoid cultures derived from patients with advanced prostate cancer. Cell 2014; 159: 176-87.

89. Junker K, Heinzelmann J, Beckham C, Ochiya T, Jenster G. Extracellular Vesicles and Their Role in Urologic Malignancies. Eur Urol 2016.

90. Di Vizio D, Kim J, Hager MH, Morello M, Yang W, Lafargue CJ, et al. Oncosome formation in prostate cancer: association with a region of frequent chromosomal deletion in metastatic disease. Cancer Res 2009; 69: 5601-9.

91. Kato T, Mizutani K, Kameyama K, Kawakami K, Fujita Y, Nakane K, et al. Serum exosomal P-glycoprotein is a potential marker to diagnose docetaxel resistance and select a taxoid for patients with prostate cancer. Urol Oncol 2015; 33: 385 e15-20.

92. Ryan CJ, Smith MR, Fizazi K, Saad F, Mulders PF, Sternberg CN, et al. Abiraterone acetate plus prednisone versus placebo plus prednisone in chemotherapy-naive men with metastatic castration-resistant prostate cancer (COU-AA-302): final overall survival analysis of a randomised, double-blind, placebo-controlled phase 3 study. Lancet Oncol 2015; 16: 152-60. 